\title{
Ушаков Е.В. \\ Проблемы расширения технической коммуникации в современной медицинской практике
}

Российская академия народного хозяйства и государственной службы при Президенте Российской Федерации (Северо-Западный институт управления РАНХиГС)

(Россия, Санкт-Петербург)

doi: 10.18411/trnio-10-2021-156

\section{Аннотация}

Статья посвящена проблемам искажения коммуникации в медицинской практики. Затрагиваются вопросы ригидности современной медицинской коммуникации, разрушения системы традиционных гуманитарных ценностей врачебного дела и связанные с этим моральные проблемы. Делается вывод о том, что клиническая практика страдает от засилья технической коммуникации, что ведет к врачебным ошибкам.

Ключевые слова: биомедицинская этика, философия медицины, коммуникация в медицине, отношения врач - пациент, моральные проблемы современной медицины.

\section{Abstract}

The article is devoted to the problems of distortion of communication in medical practice. The issues of rigidity of modern medical communication, destruction of the system of traditional humanitarian values of medical practice and related moral problems are touched upon. It is concluded that clinical practice suffers from the dominance of technical communication, which leads to medical errors.

Keywords: biomedical ethics, philosophy of medicine, medical communication, relationships doctor - patient, moral problems of contemporary medicine.

Медицинская сфера стремится стать все менее зависимой от субъективности и врачей, и пациентов. С развитием технологий она производит все больше биомедицинской информации.

Характерным примером этой тенденции объективизации клинических данных является продолжающееся продвижение лабораторной науки в клиническую практику. В классическом клиническом понимании, лабораторная диагностика является вспомогательным методом обследования: проведя первичное клиническое обследование больного, доктор должен решить, какие дальше полезно назначить дополнительные обследования. Однако с развитием лабораторной науки, которая уже стала самостоятельной индустрией в рамках медицинского учреждения, лаборатория выходит за рамки отведенных ей вторичных функций и сама активно идет навстречу лечащему врачу. Сегодня ускоренно формируется собственная рациональная тактика лабораторного исследования. По представлениям современной «философии» клинической лаборатории, принятие решений о назначении обследований остается за лечащим врачом, однако специалисты лаборатории должны инициативно работать во взаимодействии с ним, консультируя его по вопросам выбора наиболее совершенной группы тестов и получения наиболее точной и полезной диагностической информации [1, с. 178-179]. действовать.

Классический врачебный регулятив «слово лечит» фактически прекращает

При этом все действия лечащего врача оказываются существенно определенными действующими стандартами, протоколами, клиническими руководствами. На практике становится заметной тенденция к некоему упрощенному, стандартизированному поиску и принятию клинических решений, пусть даже пока и не формализованная с помощью научно разработанных моделей разработки решений (decision-making). Этому способствует также и производственная среда клинико-технологических процессов, ориентированных на массовое обслуживание пациентов. 
Стандартизация решений проявляется как стремление искать и находить типовые решения преимущественно опираясь на прямое взвешивание величин пользы против вреда, полученных из надежных источников клинических убеждений (в первую очередь и из научной литературы - привлечение доказательных свидетельств). Такой подход вызывает определенную озабоченность. Ведь «уравнение вреда и пользы» является лишь абстрактом из всей текущей ситуации, к тому же весьма усредненным. Научная оценка риска извлекается из исследований, где выясняется лишь некоторый средний ожидаемый риск, сопряженный с внутренними свойствами медицинских технологий. Это не устраняет неопределенность относительно каждого индивидуального клинического случая.

Достаточно привести только один пример. Сбор данных о состоянии пациента и вынесение врачебных назначений производятся специалистом в типичных условиях весьма схематично. С провалом диагностической гипотезы (скажем, по поводу язвенной болезни) специалист генерирует следующую гипотезу (скажем, предполагает холецистит) и назначает новые обследования. При этом врач фактически лишь скользит по поверхности клинической картины, не давая себе труда более детально разобраться в состоянии пациента.

Но, как известно, медицинская практика полна ситуациями, когда при наличии «богатой» симптоматики у больного не обнаруживается никакого определенного органического расстройства. Проблема пациента может лежать совсем в другой плоскости в сфере так называемой психосоматической медицины, и чем быстрее врач поймет это, тем скорее прекратится чреватый ятрогенным риском диагностический поиск [2, с. 21]. Однако наработанные шаблоны мышления склоняют технически ориентированных клиницистов продолжать диагностические тесты, не приглядываясь более внимательно к собственно личности своего пациента, характеру его жалоб и уклоняясь от более подробного разговора с ним.

Ригидная коммуникативная практика влияет и на обсуждение моральных проблем в клинике. Известный специалист в области медицинской этики Б. Дженнингс указывает, что широкий спектр принимаемых решений в современной медицине сегодня существенно предопределен формальными процедурами и эксплицитными правилами. Эти правила устанавливают, какой тип решения должен быть принят, с помощью каких ресурсов и т.п. Но это фактически означает значительный этический сдвиг: субъекты решений сегодня не столько находят морально значимые решения с помощью размышления, сколько, скорее, конструируют их [3].

Феномен технизации отношений врач - пациент в современных условиях тесно связан в том числе с таким явлением, как нарастание неопределенности и риска медицинских вмешательств. Как отмечает Б. Барнес, здесь наблюдается противоречивый процесс: для того, чтобы справиться с неопределенностью, которую несут нам хирургические вмешательства, генетическое тестирование и другие действия, у нас возникает настоятельная потребность в получении все более обширной и точной технической информации. Но все большая зависимость от этой информации подрывает сами отношения между экспертом и непрофессионалом (пациентом, потребителем): чем сильнее эти отношения основываются на технических знаниях, а не на доверии, тем больше в этих отношениях нарушается их исходно моральная основа. Восприятие пациентом врача как морального субъекта заменяется обсуждением чисто технических оценок. Но в итоге пациент оказывается склонен все меньше доверять эксперту именно потому, что тот является только технически компетентным специалистом, а не принимает моральные обязательства защитника пациента. Становление же более медицински компетентного пациента еще сильнее отдаляет его от врача и расширяет пропасть взаимного недоверия с обеих сторон [4].

Важной особенностью нынешнего медицинского языка является его активное оперирование количественными данными.

Это, однако, в большей мере точка зрения профессионального медицинского сообщества. Пациенты же имеют весьма различные предпочтения по поводу предоставляемой им клинической информации, зависящие от множества факторов 
(социальный и образовательный уровень, возраст, состояние здоровья, конкретная клиническая ситуация и др). Есть пациенты, которые считают количественные данные наиболее рациональной формой информирования. Но многие больные предпочитают качественные сведения. Проблема предоставления врачом пациенту клинической информации сегодня активно обсуждается в литературе [5]. При этом многие авторы подчеркивают важность такой темы, как опасность манипуляций информацией в клинических условиях.

Как один из возможных подходов, сегодня в индустриальных странах активно развивается целая индустрия так называемых «средств поддержки решений» (decision aids). Эти средства должны помочь формированию «профессионального пациента», способного самостоятельно принимать информированные решения. Это формы, которые адресованы непосредственно пациенту и содержат необходимую ему достоверную, современную информацию по различным медицинским проблемам. К «средствам поддержки» относятся различные специализированные печатные материалы (брошюры, буклеты и т.п.), фильмы, ресурсы Интернета и другие возможности. Однако пока это предприятие находится на начальной стадии и содержит много нерешенных проблем. По понятным причинам, это начинание критикуют также многие клиницисты.

Технизированные коммуникативные практики медицины являются сегодня повсеместной, глубоко укоренившейся практикой. При обращении к врачу (особенно в специализированный центр) пациент уже заранее знает, что он встретит технизированное отношение и стиль решения его проблем. Но значение технодискурса выходит за пределы просто профессионального применения медицинских технологий. Мы должны видеть его значение также в деперсонализации взаимоотношений с пациентами, снижении способности креативного поведения и нестандартных решений, унификации проблем пациентов, а также в усилении властных различий врача и пациента, устранении гуманитарных составляющих медицинской помощи, в том числе в выветривании такого классического терапевтического фактора, как врачебное слово.

$$
* * *
$$

1. Комаров Ф.И., Коровкин Б.Ф., Меньшиков В.В. Биохимические исследования в клинике. М., Элиста, 2001.

2. Любан-Плоцца Б., Пельдингер В., Крегер Ф. Психосоматический больной на приеме у врача. - СПб., 1996.

3. Jennings B. Possibilities of consensus: towards democratic moral discourse // Journal of Medicine and Philosophy, 1991, 16, p. 447-463.

4. Barnes B. Biotechnology as Expertise // O`Mahony P. (ed). Nature, Risk, and Responsibility. London: Macmllian, 1999. - P. 52-68.

5. Edwards A.G.K., Hood K, Matthews E.J., et al. The effectiveness of one-to-one risk communication interventions in health care: a systematic review // Med. Decis. Making 2000; 20, p. 290-297. 